http://dx.doi.org/10.18675/1981-8106.vol24.n45.p76-95

\title{
Avaliação do impacto de um programa de educação sexual no primeiro ciclo de escolaridade
}

\author{
Pedro Miguel Ferreira \\ Departamento de Ciências do Comportamento e Sociais do ISMAI, Maia, Portugal \\ pedro_neto86@hotmail.com \\ Marisalva Fávero \\ Departamento de Ciências do Comportamento e Sociais do ISMAl, Maia, Portugal \\ mfavero@ismai.pt \\ Amaia DelCampo \\ Universidade de Salamanca, Espanha. \\ acampo@usal.es
}

Educação: teoria e prática, Rio Claro, SP, Brasil - elSSN: 1981-8106

Está licenciada sob Licença Creative Common

\section{Resumo}

Pretendeu-se com este estudo avaliar um programa de educação sexual (SEC) aplicado aos/às alunos/as do terceiro ano de escolaridade, que foi elaborado de acordo com a lei n.o 60/2009 em Portugal. O SEC é formado por cinco sessões. Para a avaliação do programa utilizamos metodologia qualitativa, com entrevista pré e pós aplicação do programa a dois grupos de alunos/as de oito e nove anos de idade: 16 do grupo experimental (participantes do SEC) e 11 do grupo de controle. As entrevistas foram analisadas através de análise de conteúdo. Antes da aplicação do programa, ambos os grupos possuíam alguns conhecimentos na área da sexualidade. Por outro lado, possuíam ideias erradas, além de inúmeros estereótipos de género. Após a aplicação do SEC, verificou-se um aumento dos conhecimentos no grupo experimental, comparativamente ao grupo de controle, mas em ambos os grupos persistiram os estereótipos de género. Os resultados indicam que a lei da educação sexual não vai ao encontro das necessidades específicas deste grupo etário ao não salientar a importância de trabalhar, nos programas de educação sexual para o primeiro ciclo, os estereótipos de género e por consequência de desigualdades de género.

Palavras-chave: Educação sexual. Avaliação. Estereótipos de género. Desigualdades de género.

\section{Assessing the impact of a sex education program in primary education}




\begin{abstract}
This study intended to evaluate a sex education program (SEC) for the students of third grade, which was prepared according to directions of the law 60/2009 in Portugal. The SEC program consists of five sessions. For the evaluation of the program it had been used a qualitative methodology based on interviews before and after application on a sample of students aged 8 and 9 years old: 16 students from the experimental group (participants of the ESC) and 11 from the control group. The interviews were analyzed by content analysis. Before implementing the program, both groups had some knowledge in the area of sexuality. In the other hand, had misconceptions and numerous gender stereotypes. After the SEC application, it was found an increase in knowledge in the experimental group, compared with the control group, but in both groups, gender stereotypes persist. The results indicate that the sex education Portuguese law is unable to point the specific needs of this age group, by not to stressing the importance of working in the sex education programs for the first cycle the gender stereotypes and therefore, gender inequalities.

Keywords: Sex Education. Evaluation. Gender Stereotypes. Gender Inequalities.

\section{Evaluación del impacto de un programa de educación sexual en el primer ciclo de escolaridad}

\title{
Resumen
}

Con este estudio se pretendió evaluar un programa de educación sexual (SEC) aplicado a los/las alumnos/as del tercer año de escolaridad, que se elaboró de acuerdo con la ley n.60/2009 en Portugal. El SEC está formado por cinco sesiones. Para la evaluación del programa utilizamos una metodología cualitativa, con entrevista pre y pos aplicación del programa a dos grupos de alumnos/as de ocho y nueve años de edad: 16 del grupo experimental (participantes del SEC) y 11 del grupo de control. Las entrevistas se analizaron a través de análisis de contenido. Antes de la aplicación del programa, ambos grupos poseían algunos conocimientos en el área de sexualidad. Por otro lado, poseían ideas equivocadas, además de innúmeros estereotipos de género. Después de la aplicación del SEC, se verificó un aumento de conocimientos en el grupo experimental, comparativamente con el grupo de control, pero en ambos grupos persistieron los estereotipos de género. Los resultados indican que la ley de la educación sexual no va al encuentro de las necesidades específicas de este grupo etario al no destacar la importancia de trabajar, en los programas de educación sexual para el primer ciclo, los estereotipos de género y, por consecuencia, de desigualdades de género.

Palabras clave: Educación sexual. Evaluación. Estereotipos de género. Desigualdades de género.

\section{Introdução}

Abordar a Educação Sexual é falar de educação intencional, global, completa, constante e ao longo de toda a vida, uma vez que a sexualidade está presente desde o 
nascimento até à morte, diversificando-se conforme as etapas da vida (CASTAÑÓN, 2007; FÁVERO et al., 2012; RAMALHO, 2008; SIECUS, 2013).

É de salientar que a sexualidade é dissemelhante em cada fase do desenvolvimento humano. Como tal, os interesses sexuais e os comportamentos mudam de acordo com a idade, adotando características próprias em cada ciclo da vida (NEDEFF, 2001). Assim, o modo como as pessoas experienciam e expressam a sexualidade é divergente para cada indivíduo (CAMARGO; RIBEIRO, 2003; SOUTHARD; KELLER, 2009).

Durante muitos séculos foi negada a sexualidade nas crianças, existindo na atualidade igualmente pouco espaço para que se expresse. Tradicionalmente, a infância está associada a valores como a ingenuidade, inocência ou pureza e, como tal, não poderia estar "manchada" pelo sexo, sendo este historicamente considerado sujo, pecaminoso e motivo de patologias físicas e degenerações morais (ARNA; LLARIO, 2006).

A fase do desenvolvimento entre os seis e os doze anos, que coincide habitualmente com a entrada na escola, e que finaliza em torno dos dez/doze anos com o início da puberdade, possui as seguintes características ao nível do seu desenvolvimento afetivo-sexual: transformações corporais lentas; exploração do corpo e suas potencialidades; clarificação da imagem corporal; consolidação da identidade sexual; curiosidade pelas diferenças corporais, gravidez, parto e sexualidade dos/as pais/mães ou dos adultos em geral; constituição de grupos do mesmo sexo, vivenciando sentimentos flutuantes em relação ao sexo oposto; utilização de palavras relativas à sexualidade; início da seleção das amizades; dependência das normas e modelos dos adultos significativos, mas tornando-se afetivamente menos dependentes da família e início do processo de interiorização da moral sexual (MARQUES; VILAR; FORRETA, 2002).

\section{Educação Sexual}

Diversos estudos têm vindo a confirmar a tese de que a educação sexual intencional contribui para a vivência mais saudável e satisfatória da sexualidade, por 
exemplo, adiando o início das relações sexuais, favorecendo a adoção de comportamentos sexuais seguros, entre outros (JOHNSON et al., 2011; HAYTER et al., 2008; MACÁRIO, 2010; POOBALAN et al., 2009).

Em Portugal converteu-se num direito e numa obrigação a partir dos primeiros anos escolares, uma vez que recentemente foi regulamentada a Lei n.o 60/2009, de 6 de Agosto, que estabelece a Educação Sexual nos estabelecimentos de ensino básico e do secundário.

Todavia, mesmo regulamentada por lei, a implementação da Educação Sexual intencional nas escolas tem encontrado muitos obstáculos. Esta situação se deve em parte à deficiência na formação dos/as professores/as, à resistência organizada de alguns grupos de pressão, ao processo de educação informal que gera conhecimentos erróneos e atitudes negativas e por ser um assunto ainda tabu para a maioria dos/as professores/as ou por eles não serem cientificamente competentes (FÁVERO; MENESES; BILIMÓRIA, 2011; VEIGA et al., 2006).

A Educação Sexual alude à educação sobre a sexualidade (HIRD, 2003), tendo emergido como uma reação ao conservadorismo moral. Diante do silêncio das famílias e da sociedade foi necessário que os/as profissionais atuassem e abordassem a sexualidade com os/as jovens, numa vertente de esclarecimento e libertação pessoal (VILAR, 2005).

Os programas de Educação Sexual devem ser centrados em objetivos, tais como a aquisição de conhecimentos e o desenvolvimento de atitudes e competências pessoais e sociais, designadamente de identificação e clarificação de valores, gestão das emoções, comunicação relacional, tomada de decisões, resolução de problemas e assertividade. Desta forma, na Educação Sexual intencional não poderá existir lugar para a defesa de teorias pessoais ou crenças religiosas, devendo a informação ser a mais rigorosa e emancipatória e, por consequência, derivada de um estudo científico constante (RAMIRO; MATOS; VILAR, 2008).

A Educação Sexual começa muito cedo, sendo descrita como o contínuo de influências, especialmente a partir da família nos primeiros anos de vida e mais 
tardiamente pela escola e por outros agentes sociais (KAKAVOULIS, 2001; TURNBULL; WERSCH; SCHAIK, 2008).

A abordagem da sexualidade na escola é um elemento essencial de todos os sistemas de ensino de qualidade, que prepara os/as alunos/as para a participação na sociedade como cidadãos responsáveis. A ausência dessa educação, aliada à ignorância, medo ou a resposta não fundamentada, tem vindo a sustentar o aumento das taxas de gravidez indesejada e infecções de transmissão sexual (GOLDMAN, 2008).

Nesse sentido, o objetivo da presente pesquisa consiste em analisar os conhecimentos acerca de temáticas da sexualidade em alunos/as do terceiro ano de escolaridade, antes e depois da implementação de um programa de Educação Sexual. Mais concretamente, pretende ver respondidas as seguintes questões de investigação: (1) Quais os conhecimentos dos/as alunos/as sobre a sexualidade, antes e depois da aplicação de um programa de Educação Sexual?; (2) Iremos observar alterações nos conhecimentos dos/as alunos/as após a aplicação do programa de Educação Sexual?; (3) A lei da educação sexual (60/2009) vai ao encontro das necessidades específicas deste grupo etário?

\section{Método}

Participantes

Esse estudo teve a participação de vinte e sete crianças, entre os oito e os nove anos, distribuídos por duas turmas do terceiro ano de escolaridade, sendo uma delas o alvo da intervenção do programa de Educação Sexual (Grupo Experimental) e a outra o Grupo de Controle. O Grupo Experimental é constituído por nove meninos e sete meninas e o Grupo de Controle por duas meninas e nove meninos. Os/As participantes pertencem a uma instituição de ensino privado da zona norte de Portugal e provêm de famílias de nível socioeconómico cultural médio alto. Os critérios de inclusão foram: alunos/as do primeiro ciclo de escolaridade; presença nas duas entrevistas realizadas (pré-teste e pós-teste) e frequência das várias sessões de Educação Sexual, para o Grupo Experimental. 
Instrumentos de coleta de dados

Os dados foram recolhidos por meio da entrevista de grupo, semiestruturada (BOGDAN; BIKLEN, 1994), elaborada com base em alguns temas propostos na Lei 60/2009, de 6 de Agosto. Igualmente foram tidos em conta os temas lecionados na escola no referido nível escolar. As entrevistas semiestruturadas possibilitaram-nos introduzir ao longo da sua realização questões adicionais em complemento ao que estava previamente estabelecido (MINAYO, 2006). A entrevista contém os seguintes tópicos: sexualidade/educação sexual; corpo humano; puberdade; reprodução humana e papéis sexuais/género.

\section{Procedimentos}

Após ter-se obtido a autorização dos diretores do Colégio para a realização do estudo, os pais e mães foram contatados/as e informados/as sobre os objetivos e procedimentos de coleta de dados da investigação. Depois de obtidos os seus Termos de Consentimento Livre e Esclarecido assinados, realizou-se o pré-teste, em ambos os grupos, e as sessões de Educação Sexual no Grupo Experimental. Uma vez terminado o programa, passaram três semanas até à realização do pós-teste nos dois grupos.

\section{Tratamento dos dados}

As entrevistas foram transcritas e submetidas à análise de conteúdo (BARDIN, 1979), e, com a participação de quatro juízes, para se garantir a fidedignidade das categorias, a informação foi categorizada em áreas temáticas. Segundo Bardin, a análise de conteúdo é

\footnotetext{
um conjunto de técnicas de análise das comunicações visando obter, por procedimentos, sistemáticos e objetivos de descrição do conteúdo das mensagens, indicadores (quantitativos ou não) que permitam a inferência de conhecimentos relativos às condições de produção/recepção (variáveis inferidas) destas mensagens. (1979, p. 42).
}

As categorias apresentadas foram constituídas a priori, na formulação do roteiro da entrevista, e as subcategorias, a posteriori, na análise das entrevistas. 
Seguidamente são apresentadas quatro tabelas de categorização referentes às entrevistas efetuadas e expostas pela seguinte ordem: pré-teste no Grupo Experimental; pré-teste no Grupo de Controle; pós-teste no Grupo Experimental e pósteste no Grupo de Controle.

Tabela 1: Categorização do pré-teste no Grupo Experimental

\begin{tabular}{|c|c|c|}
\hline \multicolumn{2}{|l|}{ Categorias } & Subcategorias \\
\hline \multicolumn{2}{|l|}{ Sexualidade } & $\begin{array}{l}\text { Relacionamento sexual/ Reprodução humana/Sexo- } \\
\text { Género }\end{array}$ \\
\hline \multicolumn{2}{|c|}{ Educação Sexual } & $\begin{array}{l}\text { Aparelho genital/Crescimento animal/Crescimento } \\
\text { humano/Reprodução animal/Reprodução humana }\end{array}$ \\
\hline $\begin{array}{l}\text { Corpo } \\
\text { Humano }\end{array}$ & Diferenças & Características de género/Físicas \\
\hline \multirow{2}{*}{ Puberdade } & Significado & Pobreza/Sexualidade \\
\hline & Transformações & Cognitivas/Físicas/Sociais/Vivência da sexualidade \\
\hline \multirow{3}{*}{$\begin{array}{c}\text { Reprodução } \\
\text { Humana }\end{array}$} & Concepção & Ato sexual/Células reprodutoras \\
\hline & Gravidez & Barriga/Ovários \\
\hline & Parto & Barriga/Pénis/Umbigo/Vagina \\
\hline \multicolumn{2}{|c|}{ Papéis Sexuais/Género } & Estereótipos/Igualdades \\
\hline
\end{tabular}

Tabela 2: Categorização do pré-teste no Grupo de Controle

\begin{tabular}{lll}
\hline Categorias & \multicolumn{1}{c}{ Subcategorias } \\
\hline Sexualidade & & $\begin{array}{l}\text { Orientação sexual/Relacionamento } \\
\text { sexual/Sexologia/Sexual/Sexy }\end{array}$ \\
\hline Educação Sexual & $\begin{array}{l}\text { Corpo humano/Crescimento/ Relacionamento } \\
\text { sexual/Reprodução humana/Sexualidade }\end{array}$ \\
\hline $\begin{array}{l}\text { Corpo } \\
\text { Humano }\end{array}$ & Diferenças & Características de género/Físicas \\
\hline Puberdade & Significado & Pobreza/Puberdade \\
\cline { 2 - 3 } Transformações & Físicas/Vivência da sexualidade \\
\hline Humana & Concepção & Ato sexual/Corrida/Células reprodutoras \\
\cline { 2 - 3 } & Gravidez & Barriga/Corrida/Células reprodutoras \\
\cline { 2 - 3 } Parto & Barriga/Vagina \\
\hline Papéis Sexuais/Género & Estereótipos/lgualdades \\
\hline
\end{tabular}

Tabela 3: Categorização do pós-teste no Grupo Experimental

Categorias Subcategorias




\begin{tabular}{lll}
\hline Sexualidade & \multicolumn{2}{c}{$\begin{array}{l}\text { Família/Relacionamento sexual/Reprodução } \\
\text { humana/Sexo-Género/Símbolo sexual/masculino- } \\
\text { feminino }\end{array}$} \\
\hline Educação Sexual & \multicolumn{2}{c}{$\begin{array}{l}\text { Corpo humano/Diferenças entre os sexos/ } \\
\text { Diversidade sexual/ Família/ Opinar/ Puberdade/ } \\
\text { Reprodução humana/Sentimentos/Emoções }\end{array}$} \\
\hline Corpo Humano & Diferenças & $\begin{array}{l}\text { Caracteres sexuais secundários/ } \\
\text { Características de género/Físicas }\end{array}$ \\
\hline Puberdade & Significado & $\begin{array}{l}\text { Fase de mudanças físicas/Fase de } \\
\text { transição }\end{array}$ \\
\cline { 2 - 3 } & Transformações & Físicas \\
\hline Reprodução Humana & Concepção & Ato sexual/Células reprodutoras \\
\hline Gravidez & Barriga \\
\hline Parto & Barriga/Vagina \\
\hline Papéis Sexuais/Género & & Estereótipos/Igualdades \\
\hline
\end{tabular}

Tabela 4: Categorização do pós-teste no Grupo de Controle

\begin{tabular}{|c|c|c|}
\hline Categorias & \multicolumn{2}{|c|}{ Subcategorias } \\
\hline Sexualidade & \multicolumn{2}{|c|}{$\begin{array}{l}\text { Aparelho genital/Orientação sexual/ Relacionamento } \\
\text { sexual/Sexapel/Sexual }\end{array}$} \\
\hline Educação Sexual & \multicolumn{2}{|c|}{$\begin{array}{l}\text { Conduta sexual/Contracepção/Corpo humano/ } \\
\text { Crescimento/Relacionamento sexual/Reprodução } \\
\text { humana/Sexualidade }\end{array}$} \\
\hline Corpo Humano & Diferenças & $\begin{array}{l}\text { Características de género/Físicas/Papéis } \\
\text { sexuais/género/Vivência da sexualidade }\end{array}$ \\
\hline \multirow[b]{2}{*}{ Puberdade } & Significado & Crescimento/Pobreza \\
\hline & Transformações & $\begin{array}{l}\text { Cognitivas/Emocionais/Físicas/Vivência da } \\
\text { sexualidade }\end{array}$ \\
\hline \multirow{3}{*}{ Reprodução Humana } & Concepção & Ato sexual/Corrida-Células reprodutoras \\
\hline & Gravidez & Barriga/Células reprodutoras \\
\hline & Parto & Barriga/Vagina \\
\hline Papéis Sexuais/Género & & Estereótipos \\
\hline
\end{tabular}

\section{Resultados no Grupo Experimental}

Para proteger a identidade dos/as participantes foram designados por um " $\mathrm{P}$ " (participante) as falas dos/as alunos/as, sendo que o " $\mathrm{P}$ " com números refere-se ao meninos e "P" com letras às meninas. 


\section{Sexualidade}

Quanto aos resultados da entrevista pré-teste no Grupo Experimental, foi possível depreender das respostas dos/as participantes sobre a expressão "sexualidade" três subcategorias, designadamente: relacionamento sexual; reprodução humana e sexo/género. Essas foram mais direcionadas para a subcategoria "reprodução humana", com metade das respostas (seis), dividindo-se as restantes pelas duas outras subcategorias (três respostas cada). No pós-teste as respostas dos/as alunos/as fizeram referência a cinco subcategorias, especificamente: família; relacionamento sexual; reprodução humana; sexo/género e símbolo sexual masculino/feminino. Ressalvamos que as subcategorias "relacionamento sexual" e "reprodução humana" obtiveram o maior número de respostas, com seis cada, seguindo-se a "família" com três respostas e "sexo/género" e "símbolo sexual masculino/feminino" com uma resposta cada.

\section{Educação Sexual}

Os conhecimentos dos/as alunos/as no que toca às aprendizagens em Educação Sexual prendem-se essencialmente ao aparelho genital, crescimento animal e crescimento humano, bem como reprodução animal e reprodução humana. A subcategoria "reprodução humana" ganha destaque com a maior parte das respostas (seis), ficando as demais com apenas uma resposta cada. Na segunda entrevista as subcategorias evidenciadas foram: corpo humano; diferenças entre os sexos; diversidade sexual; família; opinar; puberdade; reprodução humana e sentimentos/emoções. A "puberdade" foi a subcategoria com maior número de respostas (oito), seguida da "reprodução humana" com sete e "corpo humano" com cinco. Com menos ficaram as subcategorias "diferenças entre os sexos" com quatro respostas, "sentimentos/emoções" com três, e "diversidade sexual", "família" e "opinar" com uma resposta cada.

\section{Corpo Humano}


Quanto à temática do corpo humano, os/as participantes foram capazes de enumerar as partes exteriores, sendo os membros superiores/inferiores, assim como as partes que constituem o rosto, os mais nomeados. Já nas diferenças entre os sexos, os/as alunos/as descreveram-nas nas seguintes subcategorias: características de género e físicas. No total das dezenove respostas obtidas, catorze foram direcionadas para as diferenças físicas, enquanto as restantes destinadas às características de género. É de realçar que grande parte das diferenças físicas mencionadas pelos/as participantes foi direcionada para os órgãos genitais masculinos e femininos. Após a intervenção, os/as alunos/as foram igualmente capazes de explanar com diversidade as várias partes que o constituem. Nas diferenças entre os sexos surgiram as subcategorias "caracteres sexuais secundários", "características de género" e "físicas". A subcategoria "caracteres sexuais secundários" auferiu doze respostas, "físicas" dez respostas e "características de género" duas respostas.

\section{Puberdade}

No que se refere à puberdade, no pré-teste, os conhecimentos do seu significado fixaram-se nas seguintes ideias: P7: "Pobre"; PB, PC, e PG: "Uma pessoa pobre"; P2: "Alguma coisa que tem a ver com a sexualidade"; P1: "É quando, acho que é quando as meninas ou meninos se juntam num grupo para falar de pessoas do outro sexo"; PA: "Eu já ouvi, mas acho que significa outra coisa" (contrariando a ideia dos/as colegas em referir a puberdade como sendo uma pessoa pobre). Por outro lado, nas transformações da puberdade, estas foram retratadas ao nível cognitivo, físico, social e na vivência da sexualidade. Destacam-se as mudanças físicas como aquelas mais proferidas pelos/as alunos/as. Das trinta e uma respostas, apenas uma foi direcionada para as transformações cognitivas e três para as mudanças sociais, como para a vivência da sexualidade. Por outro lado, num segundo momento, os conhecimentos do tema da "puberdade", quanto ao seu significado, foram na direç̧ão das seguintes subcategorias: fase de mudanças físicas e fase de transição. A subcategoria "fase de mudanças físicas" foi direcionada com onze respostas, enquanto "fase de transição" 
com sete respostas. Já na questão das transformações decorrentes da puberdade, estas foram representadas apenas quanto ao seu nível físico.

\section{Reprodução Humana}

Nesta categoria foram perceptíveis os conhecimentos que estes/as participantes possuíam sobre a concepção, gravidez e parto. Quanto à concepção, dez respostas foram dirigidas para a subcategoria "ato sexual", enquanto quatro para "células reprodutoras". Na questão da gravidez, nove respostas foram para a subcategoria "barriga", enquanto cinco para "ovários". No que se refere ao parto, no total das doze respostas obtidas, cinco delas foram no sentido de referir a vagina e a barriga na mesma resposta, logo de seguida com quatro respostas para a vagina e apenas uma resposta para barriga, pénis e umbigo. Já no pós-teste, quanto à concepção as subcategorias "ato sexual" e "células reprodutoras" obtiveram o mesmo número de respostas (seis). No tema da gravidez, as representações/conhecimentos foram apenas para a subcategoria "barriga", existindo duas das onze respostas totais, uma ideia mais detalhada acerca da permanência dos bebés antes de nascerem, aludindo para o termo "saco especial". Por fim, na categoria "parto", as ideias foram sempre para vagina ou barriga na mesma resposta, nunca em separado.

\section{Papéis Sexuais/Género}

Quando questionados/as acerca de possíveis desportos, brincadeiras e atividades pertencentes a cada sexo, as respostas dos/as participantes foram no sentido de evidenciarem estereótipos e igualdades em torno desses/as mesmos/as. Também após a intervenção, foi possível depreender igualmente duas subcategorias: estereótipos e igualdades.

\section{Discussão}

No que toca à expressão "sexualidade", os/as alunos/as antes da intervenção patentearam uma visão reduzida acerca do seu conceito, em ambos os grupos. Após a intervenção, os participantes do Grupo Experimental parecem ter adquirido 
conhecimentos e mudanças relevantes a respeito da expressão sexualidade. Denotamos assim uma evolução, neste grupo, acerca de um conceito ainda pouco estruturado nos seus quotidianos. A este respeito, as crianças interrogam-se sobre o que desconhecem, sobre o que não conhecem bem, ou, então, procuram afirmar o que já sabem (ROUYER, 2005). Tal como foi mencionado por Arnal e Llario (2006), a sexualidade nas crianças tem sido ao longo dos tempos negada, aludindo-se antes a inocência, pureza e ingenuidade. Como tal, a crença dos adultos nesta perspetiva conduz a que as próprias crianças reportem desconhecimento neste conceito, "vítimas" de uma ausência na abordagem da temática.

Verificamos no pré-teste que a percepção das crianças sobre as aprendizagens em Educação Sexual é limitada e por vezes defasada da realidade, especialmente no que se refere à subcategoria "relacionamento sexual" no Grupo de Controle. Depois da intervenção, os/as participantes ficaram mais conscientes dos verdadeiros ensinamentos neste tipo de sessões. Verificamos ideias erradas apenas por parte do Grupo de Controle na entrevista pós-teste.

Para compreender melhor a defasagem entre as opiniões, será importante analisar alguns dos comentários dos/as participantes do Grupo de Controle, no decorrer da entrevista. Assim, no pós-teste, um dos alunos refere: P15: "Eu tenho um canal Playboy", continuando um dos seus colegas: P13: "Eu fui a casa de um amigo e ele pôs no computador "porn» (pôs um CD?) não, fomos ao Google ele colocou "porn» e depois clicou nos vídeos (que idade tem o teu amigo?) tem oito, e fiquei que nojo", "Ah, eu vi um canal em que o homem estava a, a, a beijar as mamas da mulher".

$\mathrm{Na}$ verdade, a interferência dos meios de comunicação (eg. internet), e do grupo de pares, possui grande relevo nas representações do indivíduo. Neste caso particular, o predomínio da subcategoria "relacionamento sexual", como uma das aprendizagens em Educação Sexual, pode ser também decifrado pelas explorações que as crianças vão realizando individualmente ou em grupo, sem qualquer controlo parental. Pereira (2006) elucida para o facto de ser fundamental a Educação Sexual para as crianças, tendo estas direito a serem esclarecidas por toda a comunidade 
educativa, pois, na atualidade, estão mais expostas a diversos estímulos informativos sexuais oriundas da midia.

Convém salientar, por forma a explorar o fundamento das respostas proferidas pelos/as participantes do estudo, que a própria educação sexual surge de sucessivas influências, desde a família, a própria escola, bem como outros agentes socias. Este anterior pensamento é mencionado por Kakavoulis (2001), Turnbull, Wersch e Schaik (2008), e pode ajudar a compreender a razão para tais respostas, algumas delas erróneas e fruto das influências não controladas pelos agentes educativos.

Além disso, igualmente na mesma questão, um dos participantes refere a conduta sexual: "não ser gay". Como tal, para explorar um pouco mais este aspecto, sobretudo na sua significação, foi exposto pelos mesmos a seguinte justificativa: P14: "Porque isso é nojento"; P17: "E é um bocadinho estúpido"; P14: "Mais vale namorar com um bebé"; P13: "Porque depois os homens não podiam apalpar as mamas das mulheres" (risos). Tais concepções nos remetem para a necessidade de incluir e insistir na temática da diversidade na prática da Educação Sexual intencional no primeiro ciclo, para, deste modo, começarmos a romper desde cedo as atitudes homofóbicas.

Sobre o corpo humano e suas diferenças, foi necessário algum incentivo por parte do entrevistador para que os/as alunos/as referissem os órgãos genitais no préteste. As meninas demonstraram desconforto e pouco à vontade em mencioná-los, mas os meninos, após um deles tomar a iniciativa, desinibiram-se e passaram a nomeá-los. Neste seguimento, no pós-teste, os/as alunos/as do Grupo Experimental mencionaram os órgãos genitais com mais confiança e à vontade, utilizando com mais frequência os nomes científicos, ao passo que no Grupo de Controle raramente utilizaram a terminologia correta.

$\mathrm{Na}$ idade escolar as crianças desenvolvem os jogos sexuais infantis, sendo brincadeiras para a exploração do próprio corpo. Embora abarquem o corpo como um todo, a inquietação das instituições responsáveis pela educação das crianças está centrada nas manifestações genitais da sexualidade (FÁVERO, 2003; LÓPEZ, 2005). Assim, somente as atividades referidas com os órgãos genitais são alvo de repressão, passando a ideia de que não merecem valorização nem respeito (FÉLIX, 2002). 
Conforme a educação que recebem, existe a interiorização de uma moral, acerca da sua referenciação aos órgãos genitais. Considerando Castañón (2007), qualquer estudo deve encarar o pudor como um aspecto essencial, termo ligado a um sentimento de recato, reserva ou vergonha para com o sexo ou a desnudez, originando por sua vez pautas sociais de conduta.

No que reporta às diferenças entre os sexos, verificamos que após a intervenção os/as alunos/as do Grupo Experimental foram capazes de mencionar algumas das características próprias da fase da puberdade, como sendo diferenciadoras entre os sexos. Na verdade, o debate durante a intervenção acerca das transformações da puberdade refletiram-se neste ponto. Embora certas respostas, em ambos os grupos, se tenham dispersado do objetivo inicial, foram igualmente importantes, permitindo detectar-se outras representações que estes/as edificam acerca das dissemelhanças entre os sexos. No pós-teste, o Grupo de Controle patenteou ainda mais dispersão em relação ao que era pretendido, não existindo uma evolução nas aprendizagens, sendo estas apenas verificadas no Grupo Experimental.

O termo "puberdade", no pré-teste dos dois grupos, não foi esclarecido corretamente por nenhum aluno/a, constatando-se o desconhecimento total sobre o conceito. No segundo momento, apenas os/as participantes do Grupo Experimental o conseguiram explicar adequadamente, verificando-se um incremento nos seus conhecimentos, contrariamente ao Grupo de Controle.

Denotamos alterações quanto à questão das transformações da puberdade. Se, por um lado, no pré-teste do Grupo Experimental os conhecimentos iam para além das mudanças físicas, no pós-teste centraram-se exclusivamente nessas alterações. Os/as educandos/as demonstraram alguns conhecimentos antes da intervenção, contudo, verificamos que, após a mesma, estes aumentaram.

Apenas alguns alunos/as expuseram corretamente a explicação de concepção, predominando, por sua vez, apenas a ideia da necessidade do ato sexual como forma de concepção, no pré-teste, sem fazer referência às células reprodutoras. No Grupo Experimental, após a intervenção, a maioria estava mais consciente do processo, ficando os conceitos mais clarificados, o que provocou um acréscimo de saberes neste 
domínio. Fazendo um termo de comparação entre os grupos, as respostas no Grupo Experimental foram mais satisfatórias, uma vez que as referiram de um modo mais realista.

Na questão da gravidez, verificamos no Grupo Experimental ideias corretas apenas após a implementação do programa de Educação Sexual, uma vez que no préteste surgiram ideias erróneas. O Grupo de Controle manifestou concepções erradas nos dois momentos. Todavia, constatamos conhecimento por parte dos/as alunos/as, antes de qualquer intervenção, mas ainda pouco organizado. No tema do "parto", o Grupo Experimental exibiu ideias falsas que o Grupo de Controle não manifestou em nenhum dos momentos. Essas ideias dissiparam-se por completo após a realização do programa.

Por último, na categoria "Papéis Sexuais/Género", ficou demonstrado que as crianças de ambos os grupos discriminam algumas atividades, desportos e brincadeiras apenas para um dos sexos, nos dois momentos da entrevista. Parece não ter havido alterações nesta representação, por isso, consideramos ser uma área a reforçar nas ações de educação sexual em meio escolar. Não obstante, surgiu a ideia de que, independentemente do sexo, as pessoas são livres de realizarem o que mais possa agradar-Ihes.

Neste âmbito, foi efetuado um estudo em 2003, com crianças dos cinco aos seis anos, tendo como objeto o discurso acerca da sexualidade humana. Neste, foram verificadas semelhantes com os resultados do nosso estudo. Ou seja, as crianças selecionam os brinquedos e as brincadeiras tendo em conta o que é adequado para eles socialmente, carros e bolas para meninos e bonecas para as meninas. Apesar de no estudo anterior não estar em causa a avaliação de um programa de Educação Sexual, no nosso esta diferenciação entre os papéis de género foi verificada quer antes quer após a aplicação do programa. Denota-se, apesar de todas as alterações da sociedade no tocante à sexualidade, que ainda subsistem certas heranças que perduram nos tempos e vontades (FREITAS, 2006).

Na sociedade atual, pais/mães, pares, educadores/as, mídia, literatura infantil e até mesmo os conteúdos escolares, são usados para conferir um determinado papel e 
uma identidade, quer aos rapazes quer às meninas (NARDI; QUARTIERO, 2012). Desta forma, é exercida uma pressão educativa de âmbito sociossexual (LÓPEZ; FUERTES, 1999). Acerca da interiorização da moral sexual, López e Fuertes (1999) referem que as crianças nascem "amorais", todavia, é pouco a pouco que vão obtendo consciência sobre o que os adultos esperam delas, conseguindo analogamente um maior controle sobre a sua própria conduta.

Esta questão dos papéis de género, como foi possível apurar nas entrevistas, tende a ter certa resistência à mudança, uma vez que as ações de (in)formação não conseguem modificar a moral sexual já enraizada na cultura familiar.

\section{Conclusão}

Outorgamos utilidade neste trabalho, na medida em que permitiu conhecer os "saberes" dos/as estudantes, acerca de temáticas ainda tabu em alguns setores da nossa sociedade. Neste sentido, com todas as interpretações e reflexões realizadas, ambicionamos que as vindouras pesquisas se preocupem igualmente por estes temas, para assim colaborarem na melhoria da educação sexual intencional e na satisfação das necessidades dos/as que usufruem destas aprendizagens.

Após a análise dos resultados, foi possível averiguar que qualitativamente os conhecimentos dos/as participantes do Grupo Experimental sofreram uma modificação, aumentando os seus saberes acerca das temáticas da sexualidade. Desta forma aperfeiçoaram a visão acerca da expressão "sexualidade" e das aprendizagens em educação sexual, a utilização dos nomes científicos aos órgãos genitais, a definição ao conceito de "puberdade" e suas transformações e a explicação dos mecanismos de reprodução humana.

Alertamos para a utilidade de, nos futuros programas, dar-se mais importância às questões da orientação sexual e dos papéis sexuais/género. Não raras vezes, apesar de ser útil a abordagem de certos temas, existe o entrave por parte das instituições ou falta de receptividade dos/as pais e mães. Foi possível detectar que as crianças, mesmo antes de serem alvo de uma intervenção, possuem conhecimentos, alguns deturpados e preconceituosos, sendo estes auferidos pelo meio em que estão 
inseridas. Por outro lado, da maneira como está formulada, a lei da educação sexual não vai ao encontro das necessidades específicas dos/as alunos do primeiro ciclo de ensino.

Para otimizar o êxito das intervenções intencionais em educação sexual é essencial o envolvimento dos/as pais/mães, pois muitos/as deles/as defrontam-se com a falta de à-vontade para abordar os temas com os filhos e filhas. Nestes casos, pelo menos a escola assegura (ou deveria garantir), através da educação sexual intencional, que a educação para a sexualidade não seja olvidada.

Como obstáculos desta investigação, realçamos o fato de o número de sessões ter sido menor do que o desejado. Tal situação impediu investigar outros temas, como por exemplo a questão da violência sexual de menores. No entanto, foi igualmente frutuosa a execução da intervenção do modo como foi aplicado. Isto porque a educação sexual intencional, nas escolas, ainda é uma utopia, uma vez que não tem sido colocada na prática a Lei n. 60/2009, de 6 de agosto, especificamente no que diz respeito à carga horária.

Ao nível metodológico, na investigação dos conhecimentos, seria proveitoso compilar com a metodologia quantitativa, particularmente na aplicação de questionários. Todavia, atualmente não existem instrumentos que possibilitem essa avaliação em alunos/as do primeiro ciclo de escolaridade. Posto isto, seria útil começar-se a construí-los, podendo futuramente auxiliar na avaliação da eficácia dos programas de educação sexual desenvolvidos.

\section{Referências}

ARNAL, R. B.; LLARIO, M. D. La sexualidad en niños de 9 a 14 años. Psicothema, Oviedo, v. 18, n. 1, 25-30, 2006.

BARDIN, L. Análise de conteúdo. Lisboa: Edições 70, 1979. 226p.

BOGDAN, R.; BIKLEN, S. Características da investigação qualitativa. In: Investigação qualitativa em educação: uma introdução à teoria e aos métodos. Porto, Porto Editora, 1994. p. 4751. 
CAMARGO, A. M.; RIBEIRO, C. La educación sexual en lo cotidiano de la escuela. Educar, n. 31, 67-85, 2003.

CASTAÑóN, J. G. La Sexualidad: un campo de estudio permanente. Medicina Universitaria, Barcelona, n. 9, 159-160, 2007.

FÁVERO, M. Sexualidade infantil e abusos sexuais de menores. Lisboa: Climepsi, 2003. $242 \mathrm{p}$.

FÁVERO, M.; FERREIRA, P.; FEIJÓ, N., et al. A educação sexual, conceitos, modelos e legislação portuguesa. Terapia Sexual, São Paulo, v. 15, n. 1, 11 - 22, 2012.

FÁVERO, M.; MENESES, J.; BILIMÓRIA, H. Atitudes dos professores e educadores face à implementação da educação sexual na escola. Terapia Sexual, São Paulo, v. 14, p. 1, 73 $-56,2011$.

FÉLIX, I. M. Características da sexualidade na infância. In: MARQUES, A.; VILAR, D.; FORRETA, F. (Orgs.). Educação sexual no 10 ciclo: um guia para professores e formadores. Lisboa: Texto, 2002. P. 40-48

FREITAS, L. F. Do que eles se lembram! Representações dos pré-escolares acerca da sexualidade humana. Educação Sexual em Rede, 2, 5-13, 2006.

GOLDMAN, J. D. Responding to parental objections to school sexuality education: a selection of 12 objections. Sex Education, New York, v. 8, p. 4, 415-438, 2008.

HAYTER, M. et al. School nurses and sex education: surveillance and disciplinary practices in primary schools. Journal of Advanced Nursing, Malden, v. 61, p. 3, 273281, 2008.

HIRD, M. J. Thinking about 'sex' in education. Sex Education, New York, 3(3), 187-200, 2003.

JOHNSON, B.; SCOTT-SHELDON, L.; HUEDO-MEDINA, T. et al. Interventions to reduce sexual risk for human immunodeficiency virus in adolescents: a meta-analysis of trials, 1985-2008. Archives of Pediatric Adolescence Medicine, 165(1):77-84. 2011, doi:10.1001/archpediatrics.2010.251.

KAKAVOULIS, A. Family and sex education: a survey of parental attitudes. Sex Education, New York, 1(2), 163-174, 2001.

Lei n. 60/2009, de 6 de Agosto. Diário da República, 1. a série - № $151-6$ de Agosto de 2009.

LÓPEZ, F. La educación sexual de los hijos. Madrid: Pirámide, 2005. 
LÓPEZ, F.; FUERTES, A. Para compreender a sexualidade (António Marques e Lurdes Silva). Lisboa: Associação para o Planeamento da Família (originalmente publicado em 1989), 1999.

MACÁRIO, R. M. Educação sexual em contexto escolar: outro ano zero?! 2010. 144 f. Tese (Mestrado em Dinamização das Ciências em Contexto Escolar) - Universidade do Algarve, Faro, 2010.

MARQUES, A. M.; VILAR, D.; FORRETA, F. Educação sexual no 10 ciclo: um guia para professores e formadores. Lisboa: Texto, 2002.

MINAYO, M. C. O desafio do conhecimento: pesquisa qualitativa em saúde. 9. ed. Petrópolis: Vozes, 2006.

NARDI, H.; QUARTIERO, E. Educando para a diversidade: desafiando a moral sexual e construindo estratégias de combate à discriminação no cotidiano escolar. Sexualidad, Salud y Sociedad, Rio de Janeiro, n. 11, 59-87, 2012.

NEDEFF, C. C. Contribuições da sexologia sobre a sexualidade infantil nos dois primeiros anos de vida: uma revisão bibliográfica. Psicologia: Teoria e Prática, São Paulo, v. 3, p.2 , 83-91, 2001.

PEREIRA, M. M. Guia de educação sexual e prevenção do abuso. Coimbra: Pé de Página, 2006.

POOBALAN, A. et al. Characteristics of effective interventions in improving young people's sexual health: a rewiew of reviews. Sex Education, New York, v. 9, p. 3, 319336, 2009.

RAMALHO, M. J. Educação sexual em Portugal. Educação Sexual em Rede, Lisboa, n.4, 18-20, 2008.

RAMIRO, L.; MATOS, M. G.; VILAR, D. Factores de sucesso da educação sexual em meio escolar. Educação Sexual em Rede, Lisboa, n.3, 8-13, 2008.

ROUYER, M. Sexualidade: vida em família. Lisboa: Pergaminho, 2005.

SIECUS. Comprehensive sexuality education. 2013. Disponível em: $<$ www.siecus.org/index.cfm?fuseaction=Page.viewPage\&pageld=514\&parent|D=477>. Acesso em: 20, Maio, 2013.

SOUTHARD, N. Z.; KELLER, J. The importance of assessing sexuality: A patient perspective. Clinical Journal of Oncology Nursing, v. 13, n. 2, 213-217, 2009. doi:10.1188/09.CJON.213-217 
TURNBULL, T.; WERSCH, A.; SCHAIK, P. A review of parental involvement in sex education: The role for effective communication in British families. Health Education Journal, v. 67, n. 3, 182-195, 2008. doi: 10.1177/0017896908094636

VEIGA, L. et al. Sexuality and human reproduction: a study of scientific knowledge, behaviours and beliefs of Portuguese future elementary school teachers. Sex Education, New York, v. 6, n. 1, 17-29, 2006.

VILAR, D. A educação sexual faz sentido no actual contexto de mudança? Educação Sexual em Rede, Lisboa, n. 1, 8-15, 2005.

Enviado em Julho/2013 Aprovado em Outubro/2013 